\title{
Cell-mediated cytotoxicity for cultured autologous rheumatoid synovial membrane cells*
}

\author{
WILLIAM A. NEILL \\ From the Rheumatic Diseases Unit, Northern General Hospital, Edinburgh
}

SUMMARY Cytotoxicity tests were performed on cultured rheumatoid synovial membrane cells with autologous lymphocytes as effector cells. Three of 26 cultures were positive when tested at primary or first passage level, but on subsequent tests became negative. Tests based on an isotope-labelling technique and a micro-cytotoxicity assay were compared; the results appeared to correlate well. The expression of neoantigens on synovial cells was not demonstrated. Cultures initiated in medium containing hydrocortisone did not give rise to a population of synovial cells susceptible to immune lysis by autologous lymphocytes.

The histological appearance of rheumatoid synovial membrane suggests that the cellular immune response might be important in the pathogenesis of the disease. Consequently there have been a number of studies on the cytotoxic potential of lymphocytes from patients with rheumatoid arthritis (RA) towards a variety of target cells-for example, human fetal fibroblasts, ${ }^{1-3}$ Chang human liver cells, ${ }^{4}$ and allogeneic or autologous synovial cells. ${ }^{5-7}$ The investigation of Griffiths et al. ${ }^{7}$ is of particular interest because, although largely a study of allogeneic lymphocytes and target cells, it included a limited sample of cytotoxicity assays of an entirely autologous nature. These results argued against the presence of synovial cell neoantigens inducing specific immunological attack by sensitised lymphocytes.

The present study examined a larger sample of cultures of rheumatoid synovial membrane cells by 2 different cytotoxic assay systems for evidence of cytotoxicity by autologous peripheral blood lymphocytes. In an attempt to 'damp down' the potentially cytotoxic effect of activated synovial macrophages during the first few days of the synovial cells in culture some cultures were established in the presence of hydrocortisone. ${ }^{8}$

Accepted for publication 16 November 1979

Correspondence to Mr W. A. Neill, Virus Research Laboratory, Department of Bacteriology, University Medical School, Teviot Place, Edinburgh EH8 9AG.

*Extracted from a thesis submitted for fellowship of the Institute of Medical Laboratory Sciences.

\section{Materials and Methods}

TISSUE CULTURE MEDIUM (TCM)

All procedures involving synovial cells and lymphocytes were performed in Eagle's minimum essential medium (MEM) supplemented with $20 \%$ fetal calf serum (FCS), 100 units per $\mathrm{ml}$ penicillin and $100 \mu \mathrm{g}$ per $\mathrm{ml}$ streptomycin. The $\mathrm{pH}$ of the medium was adjusted to $7 \cdot 2$ by the addition of $1.4 \% \mathrm{w} / \mathrm{v}$ sodium bicarbonate. Some synovial cell cultures were initiated in TCM to which had been added hydrocortisone at a final concentration of $100 \mu \mathrm{g}$ per ml.

\section{PATIENTS}

All patients included in the study were attending the Princess Margaret Rose Orthopaedic Hospital, Edinburgh, and were classified as having definite RA.

PREPARATION OF PATIENTS' LYMPHOCYTES

Venous blood was collected into preservative-frce heparin at a final concentration of 20 units per $\mathrm{ml}$ and the mononuclear cells separated by a single step centrifugation through a Triosil-Ficoll gradient. The gradient was prepared by mixing 10 parts of $34 \%$ triosil with 24 parts of $9 \%$ ficoll. Whole blood was carefully layered on to an equal volume of the gradient and centrifuged at $400 \mathrm{~g}$ for $15 \mathrm{~min}$ at room temperature. The lymphocyte-rich layer found at the interface was removed and washed 3 times in TCM before being used in cytotoxicity assays. These cell suspensions were not further purified, so that they were generally contaminated with approximately $10-20 \%$ monocytes and $5-10 \%$ polymorphonuclear 
leucocytes but are referred to in the text as lymphocyte suspensions.

PREPARATION OF SYNOVIAL CELLS

Synovial tissue was collected at surgical synovectomy and delivered to the laboratory as quickly as possible in phosphate buffered saline (PBS). Inflamed tissue was asceptically removed from the bulk of the membrane, finely chopped with scissors, and added to an Erlenmeyer flask containing $150-200 \mathrm{ml}$ of $0.25 \%$ trysin solution. A sterile bar magnet was placed into the flask and gentle stirring commenced for 1 hour at $37^{\circ} \mathrm{C}$. The free cells were harvested into $20 \mathrm{ml} \mathrm{FCS}$, and a further volume of trypsin was added to the tissue. A total of 3 harvests were collected from each tissue. These were pooled, the cells sedimented by gentle centrifugation, resuspended in TCM, and finally counted in a Neubauer counting chamber. A final cell suspension was prepared containing $1 \times 10^{6}$ cells per $\mathrm{ml}$, and $30 \mathrm{~cm}^{2}$ plastic culture flasks were seeded with $5 \mathrm{ml}$ cell suspension. Cell cultures were grown in TCM and also in TCM containing $100 \mu \mathrm{g}$ per ml hydrocortisone (TCM-HC). Medium was changed in all cultures after 3-4 days, and those cells grown in TCM-HC were thoroughly washed and given fresh TCM without hydrocortisone. Cytotoxicity tests were carried out on primary cultures whenever possible, but when a subculture was necessary a split ratio of $1: 2$ was used after trypsinisation of the cell monolayer.

51 CR-LABELLING OF SYNOVIAL CELLS

Synovial cells were brought into single cell suspension by trypsinisation of a monolayer. The cells were counted and $1 \times 10^{6}$ target cells were mixed with $0.1 \mathrm{ml}$ FCS followed by $100 \mu \mathrm{Ci}{ }^{51} \mathrm{Cr}$-sodium chromate (Radiochemical Centre, Amersham; code CJS 4 ; specific activity $90-100 \mu \mathrm{Ci} / \mu \mathrm{g}$ chromium). Target cells were incubated in the isotope for $45 \mathrm{~min}$ at $37^{\circ} \mathrm{C}$, washed 3 times in $20 \mathrm{ml} \mathrm{TCM}$ to remove excess isotope, and finally resuspended at $1 \times 10^{5}$ labelled cells per $\mathrm{ml}$.

\section{CYTOTOXICITY TESTS}

Cell-mediated cytotoxicity (CMC) assessed by the chromium release test. Cytotoxicity tests were performed in $1.0 \mathrm{ml}$ disposable plastic tubes. To each tube was added $0.3 \mathrm{ml}$ labelled target cells and $0.3 \mathrm{ml}$ autologous lymphocyte syspension. The ratio of lymphocytes to target cells was $25: 1$. Each test was set up in triplicate and incubated for $18 \mathrm{~h}$ at $37^{\circ} \mathrm{C}$ in an atmosphere of $5 \% \mathrm{CO}_{2}$ in air. At the end of the incubation period the tubes were centrifuged at $200 \mathrm{~g}$ for $5 \mathrm{~min}$ and the supernatant removed. By counting the amount of radioactivity in the supernatant and also that of the remaining cells in the tube the percentage of isotope released from the target cells could be calculated. Control tubes without lymphocytes were set up in each experiment to measure the amount of spontaneously released isotope. In addition, cells were also incubated in an equal volume of $2 \% \mathrm{v} / \mathrm{v}$ acetic acid to measure total releaseable isotope. The gamma emissions from samples were counted in a Nuclear Enterprises NE 8312 automatic spectrometer for a minimum of 1 minute.

Calculation of cytotoxicity. For all cytotoxicity tests performed a cytotoxic index (CI) was calculated according to the following formulae:

$$
\text { (1) } \%{ }^{51} \mathrm{Cr} \text { released }=\frac{\begin{array}{c}
\text { Mean supernatant counts per } \\
\text { minute }
\end{array}}{\begin{array}{c}
\text { Mean total activity counts } \\
\text { per minute }
\end{array}} \times 100
$$

(2) Cytotoxic Index $=\frac{T R-S R}{M R-S R} \times 100$

Where: $\mathrm{TR}=\%{ }^{{ }^{51} \mathrm{Cr}}$ released from target cells by test lymphocytes (test release)

$\mathrm{SR}=\%{ }^{51} \mathrm{Cr}$ released spontaneously from target cells (spontaneous release) and

$\mathrm{MR}=\%{ }^{51} \mathrm{Cr}$ released by incubation of target cells in $2 \%$ acetic acid (maximum release).

Cell-mediated cytotoxicity assessed by microcytotoxicity assay (MA) test system. Sterile, disposable microtest tissue culture plates (Terasaki plates; Nunc) were used. These microtest plates contain 60 flat-bottomed wells, each with a capacity of 15-20 $\mu$ l. The method used was a modification of that of Bubenik et al. ${ }^{9}$ Suspensions of synovial target cells were diluted to contain 100 cells in $10 \mu \mathrm{l} \mathrm{TCM}$ and were then plated into wells of the plastic plates with an automatic dispenser attached to a $250 \mu \mathrm{l}$ Hamilton microsyringe. The microplates were then incubated for approximately $2 \mathrm{~h}$ at $37^{\circ} \mathrm{C}$ in an atmosphere of $5 \% \mathrm{CO}_{2}$ in air. The number of cells attached could then be assessed microscopically and the effector cell suspension adjusted so that the final ratio of effector to target cells was 50:1. The plating efficiency of the cells was between 30 and $50 \%$ $5 \mu \mathrm{l}$ of TCM was added to each of the control wells so that each well in the plate contained a total volume of $15 \mu \mathrm{l}$. Each test consisted of 10 control wells containing only target cells plus TCM, and 10 wells contained target cells plus effector cells from peripheral blood of the target cell donor. The microtest plates were incubated for $24 \mathrm{~h}$, washed with PBS to remove unattached target cells and effector cells, stained for 10 min with May-Grünwald stain followed by $10 \mathrm{~min}$ in 1:20 Giesma solution, and finally air dried. For counting, each well was filled with liquid paraffin and the number of cells in each 
well counted microscopically. Mean counts and standard deviation per well were calculated and the results expressed as a percent reduction in the test wells count with the mean cell count in the control wells taken as $100 \%$. Significance of difference between cell counts in test and control groups was calculated by Student's $t$ test.

\section{Results}

Cytotoxicity tests performed on synovial membrane cells with autologous effector cells and assayed by the chromium release test (CRT)

Synovial cell cultures were established from a total of 26 patients with RA by trypsinisation of membrane tissues. Cell cultures were grown in TCM (Eagle's MEM supplement with $20 \%$ fetal bovine serum) and also in TCM with added hydrocortisone at a final concentration of $100 \mu \mathrm{g}$ per ml. Wherever possible, cytotoxicity tests were performed on the synovial cells at the primary culture level, but, failing this, at the lowest possible passage number. In practice 19 of the 26 cell strains were examined by the CRT at the primary level at the first passage. None was tested after the third passage. This meant that the synovial cells were in culture for a minimum of 7 days and a maximum of 3 weeks by the time they were tested for susceptibility to cytotoxicity of autologous effector cells. A number of cell cultures were tested on more than one occasion if blood samples became available.

The results of these cytotoxicity tests are shown in Table 1. Peripheral blood lymphocytes from 3 patients induced significant cytotoxicity on autologous synovial cells that had been cultured in TCM. The cytotoxic index (CI) of these positive tests was $14 \cdot 9,16 \cdot 0$, and $20 \cdot 1 \%$, and all 3 results were significant at the $5 \%$ level by Student's $t$ test $(P<0 \cdot 05)$. One of these synovial cultures (patient 17) was positive when tested at the primary level but on subsequent testing at the second pass, the CI had decreased from 14.9 to $2 \cdot 8 \%$, and the $t$ test had become nonsignificant $(t=0.33 ; \mathrm{P}>0.05)$. Similarly, lymphocytes from patients 2 and 8 were also cytotoxic on initial testing at pass 1 but negative when tested at pass 2 .

The possibility that a zone of hyaluronic acid might surround cultured synovial cells and thereby

Table 1 Cytotoxicity of peripheral blood lymphocytes for autologous synovial membrane cells cultured in TCM

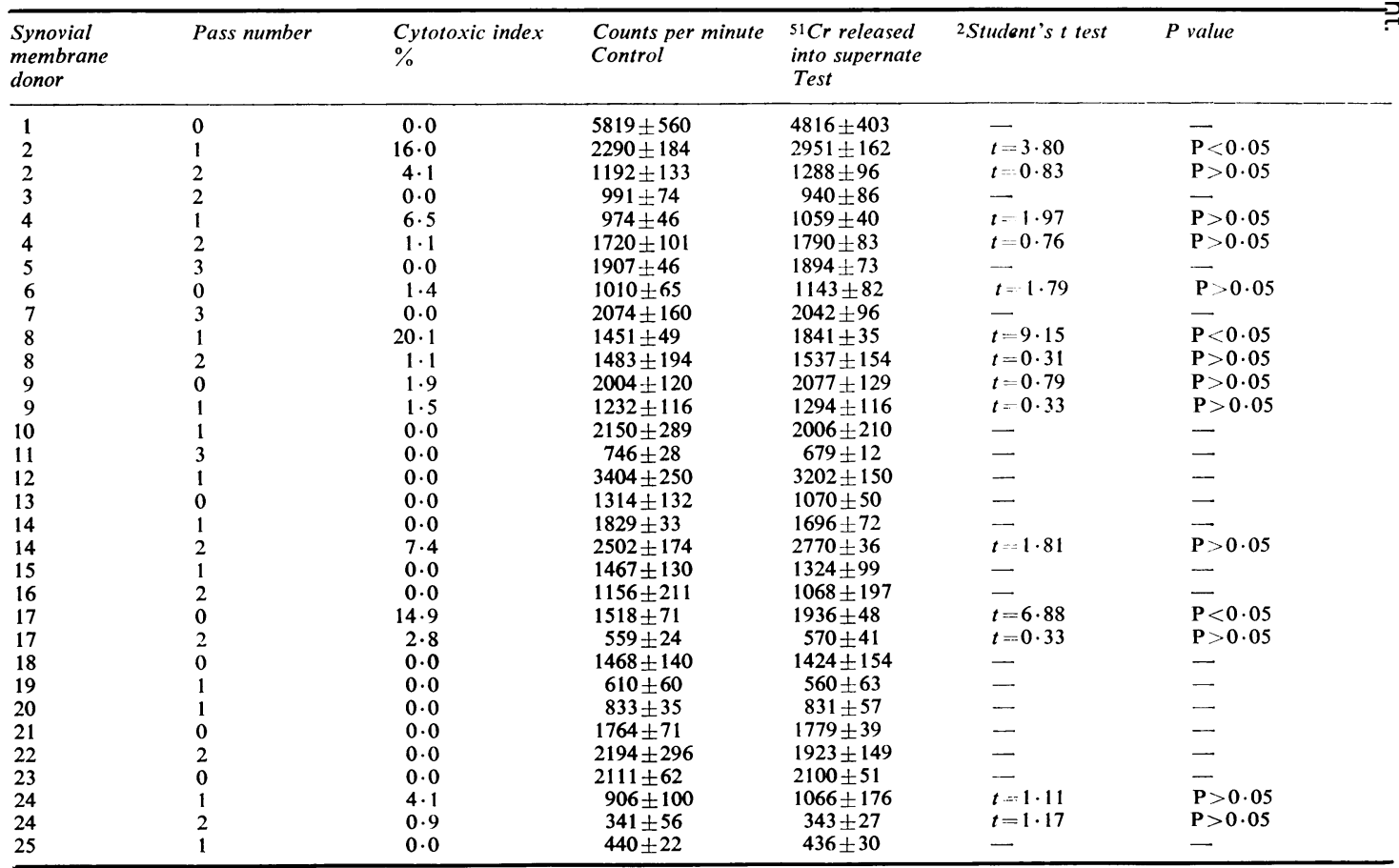

$1 \times 10451 \mathrm{Cr}-1$ abelled synovial membrane cells were incubated overnight in the presence of a 25 times excess of autologous peripheral blood mononuclear cells. The amount of isotope released into the supernate by effector cell-induced lysis of synovial cells was compared with that released in the absence of effector cells. The difference was assessed for significance by Student's $t$ test. The cytotoxic index (CI) was also calculated. 
inhibit effector cell:target cell contact was investigated. Synovial cells of 5 patients listed in Table 1 were divided into 2 aliquots after isotope labelling. While one aliquot received autologous lymphocytes immediately, the other was treated with hyaluronidase (Sigma) at a concentration of $1 \mathrm{mg}$ per $\mathrm{ml}$ for $30 \mathrm{~min}$ at $37^{\circ} \mathrm{C}$ prior to incubation with lymphocytes. Lymphocyte cytotoxicity was increased in patient 8 from $20 \cdot 1$ to $24 \cdot 1 \%$ and in patient 9 from $1 \cdot 9$ to $3 \cdot 2 \%$. Meanwhile no difference was seen in the tests performed on synovial cells from patients 1,14 , and 23, all of whom were negative throughout.

A total of 21 cytotoxicity tests were performed on 18 synovial membrane cultures initiated in TCM supplemented with hydrocortisone. Of these, 2 were positive (patients 4 and 18, of Table 1) when tested at pass 1 . At pass 2 the test on target cells from patient 4 become negative, while lymphocytes from the second patient were not available.

Cytotoxicity tests performed on autologous synovial cells in the microcytotoxicity assay (MA)

Synovial membrane cells from 14 patients with RA were examined by the MA test system for a cytotoxic response by the patients' own peripheral blood lymphocytes. Most of the target cell cultures tested were grown in TCM, while a few had been initiated in TCM containing added hydrocortisone $(100 \mu \mathrm{g}$ per $\mathrm{ml}$ ). In addition freshly trypsinised synovial cells from 6 of the 14 membranes were passed through a single cycle of freezing in liquid nitrogen followed by rapid thawing at $37^{\circ} \mathrm{C}$ and then set up in culture in TCM. This process lysed approximately $99 \%$ of the lymphoid cells present in the membrane suspensions. Viability was assessed by the trypan blue dye exclusion test. The remaining viable cells could be easily identified microscopically as fibroblasts which were then cultured in an environment almost totally freed of cytotoxic lymphoid cells.

Table 2 shows the mean numbar of remaining target cells per well in MA tests performed on 22 cultures from 14 synovial membranes. In only 1 of 13 cultures grown in TCM and 1 of 6 cultures set up after liquid nitrogen treatment was significant cytotoxicity induced by autologous lymphocytes. None of 3 cultures grown in TCM with added hydrocortisone showed a significant reduction in the number of remaining target cells. Fifteen of the cultures examined by MA were simultaneously tested by the ${ }^{51} \mathrm{Cr}$-release test. Of the 14 tests which were negative by MA 13 were also negative by CRT. One test which was positive in the MA series was negative by CRT, so that the results obtained by 2 different cytotoxicity assay systems using the same target cells appeared to correlate well.
Table 2 Cytotoxicity of peripheral blood lymphocytes for autologous synovial membrane cells by microcytoxicity assay $(M A)$

\begin{tabular}{|c|c|c|c|c|}
\hline \multirow{2}{*}{$\begin{array}{l}\text { Synovial } \\
\text { membrane } \\
\text { donor }\end{array}$} & \multirow[t]{2}{*}{ Culture } & \multicolumn{2}{|c|}{$\begin{array}{l}\text { Mean number* of synovial } \\
\text { cells per wall } \pm S D\end{array}$} & \multirow[t]{2}{*}{$\begin{array}{l}\text { Student's } \\
\text { t test }\end{array}$} \\
\hline & & Control & Test & \\
\hline $\begin{array}{r}1 \\
1 \\
3 \\
3 \\
4 \\
7 \\
8 \\
8 \\
9 \\
12 \\
13 \\
13 \\
16 \\
22 \\
22 \\
22 \\
21 \\
21 \\
23 \\
23 \\
24 \\
26\end{array}$ & $\begin{array}{l}\text { TCM } \\
\text { Nit } \\
\text { TCM } \\
\text { TCM-HC } \\
\text { TCM } \\
\text { TCM } \\
\text { TCM } \\
\text { Nit } \\
\text { TCM } \\
\text { TCM } \\
\text { TCM } \\
\text { Nit } \\
\text { TCM } \\
\text { TCM } \\
\text { TCM-HC } \\
\text { Nit } \\
\text { TCM-HC } \\
\text { Nit } \\
\text { TCM } \\
\text { Nit } \\
\text { TCM } \\
\text { TCM }\end{array}$ & $\begin{array}{r}59 \cdot 4 \pm 5 \cdot 9 \\
65 \cdot 8 \pm 5 \cdot 8 \\
49 \cdot 3 \pm 4 \cdot 4 \\
63 \cdot 3 \pm 8 \cdot 0 \\
33 \cdot 2 \pm 4 \cdot 0 \\
62 \cdot 6 \pm 4 \cdot 7 \\
67 \cdot 8 \pm 9 \cdot 1 \\
45 \cdot 4 \pm 5 \cdot 1 \\
44 \cdot 2 \pm 6 \cdot 0 \\
33 \cdot 7 \pm 4 \cdot 4 \\
53 \cdot 0 \pm 4 \cdot 9 \\
71 \cdot 6 \pm 8 \cdot 1 \\
60 \cdot 5 \pm 7 \cdot 0 \\
137 \cdot 5 \pm 15 \cdot 0 \\
62 \cdot 5 \pm 8 \cdot 8 \\
40 \cdot 9 \pm 3 \cdot 5 \\
69 \cdot 7 \pm 8 \cdot 4 \\
43 \cdot 9 \pm 3 \cdot 3 \\
75 \cdot 2 \pm 5 \cdot 1 \\
88 \cdot 4 \pm 9 \cdot 2 \\
23 \cdot 4 \pm 33 \cdot 7 \\
101 \cdot 0 \pm 12 \cdot 2\end{array}$ & 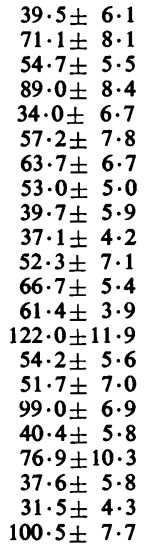 & $\begin{array}{l}P<0.001 \\
- \\
- \\
\bar{P}>0.10 \\
P>0.30 \\
\bar{P}>0.10 \\
\bar{P}>0.80 \\
P>0.10 \\
\bar{P}>0.05 \\
P>0.05 \\
- \\
\bar{P}>0.10 \\
\bar{P}<0.001 \\
\bar{P}>0.90\end{array}$ \\
\hline
\end{tabular}

* Mean number of target cells in $\mathbf{1 0}$ wells of a Terasaki microtest plate. Synovial membrane fibroblasts were established in culture in TCM, TCM with added hydrocortisone (TCM-HC), and in TCM after 1 cycle of rapid freezing in liquid nitrogen followed by thawing at $37^{\circ} \mathrm{C}$ (Nit). Target cells were added to 20 wells of a Terasaki plate to give $50-100$ adherent cells per well after 2 hours incubation at $37^{\circ} \mathrm{C}$. Autologous peripheral blood lymphocytes $\left(2.5 \times 10^{3}-5 \times 10^{3}\right.$ per well) were added to 10 wells and TCM to the 10 control wells. Plates were incubated for 24 hours, washed with PBS fixed in methanol, and stained by Giesma solution. The number of remaining target cells per well were counted, and the difference between the mean obtained in the control row compared with that of the test row by Student's $t$ test.

\section{Discussion}

In experiments involving either murine tumour cells or virus-infected target cells mixed with thymus-derived T-lymphocytes clear evidence has been obtained that there is a cellular immune response and that the effector or cytotoxic cell involved is the $\mathbf{T}$ cell. T-cell-mediated cytotoxicity of virusinfected or hapten-modified target cells in mice is restricted by the $\mathrm{H}-2 \mathrm{D}$ and $\mathrm{H}-2 \mathrm{~K}$ antigens of the major histocompatibility complex (MHC). Cytotoxic $\mathrm{T}$ cells are therefore active only against target cells sharing these antigens with the animal in which the cytotoxic cells have been raised. ${ }^{1011}$ There is also evidence to suggest that a similar MHC restriction might operate within the human HLA system. ${ }^{12} 13$ For $\mathrm{T}$ cell cytotoxicity to be expressed in neoantigenbearing synovial cells effector cells would be required to share some important HLA antigens with target cells in addition to being sensitised to the neoantigen. Allogeneic cytotoxic systems using synovial cells and $T$ cells would therefore be unlikely to reveal specific cytotoxicity, even if the target cell was 
expressing antigens against which the donor lymphocytes were sensitised. Only an entirely autologous test system would reveal $\mathrm{T}$ cell cytotoxicity.

In the present study synovial membranes cells from 25 patients with RA were tested in a chromium release assay (CRT) against autologous peripheral blood lymphocytes. The synovial target cells were tested as soon as possible after initiation in culture. This was felt to be particularly important lest neoantigen-bearing cells should be lost by repeated subculture. Previous investigators using a similar isotope release assay ${ }^{7}$ or $\mathbf{M A}^{6}$ derived their synovial target cells from explants, and cytotoxicity tests were performed after lengthy periods in culture. It can safely be assumed therefore that their target cells were pure cultures of fibroblasts, whereas those in the present study were frequently a heterogeneous mixture of synovial fibroblasts, macrophages, and undifferentiated esterase-positive staining cells which might represent the intermediate type $\mathrm{C}$ cells. Nineteen of 25 synovial cells strains were tested at either primary culture level or first subculture and all were assayed by the third. This represented a period of 1-3 weeks in culture.

Of the 3 cultures that had a positive cytotoxic index on initial testing all became negative at a subsequent level. The cell type most likely to be lost on subculture is the macrophage, and this cell might therefore be responsible for the observed cytotoxicity. The actual role of the macrophage, however, is not immediately apparent. Possibly these cells have ingested foreign antigens present in the affected tissue for processing via lymphocytes and are thereby acting as target cells for sensitised lymphocytes. Macrophage-lymphocyte clusters have been demonstrated in vitro in rheumatoid synovial fluid cultures with both autologous and heterologous lymphocytes ${ }^{1415}$ but since there was no stimulation of the involved lymphocytes these clusters were not thought to be due to the presence of antigen in the macrophages. Macrophage cytoplasmic membranes, however, have been shown to localise antigen in immunised rabbits for periods up to 1 month after injection of sensitising antigen, ${ }^{16}$ so that the possibility of antigen being present on macrophages is a possible mechanism for cell-mediated cytotoxicity.

On the other hand synovial macrophages themselves may be cytotoxic for cells bearing foreign antigens, such as Chang cells. ${ }^{17}$ Cytotoxicity was observed by Mackay et al. during only the first few days in culture and the effect was lost after 10 days. ${ }^{17}$ A similar phenomenon might have been operating in the cytotoxicity tests showing positive results in this study. If the synovial fibroblasts expressed neoantigens, then synovial macrophages, rather than the patient's blood effector cells, might exhibit aggressiveness causing cytolysis. By subculturing these synovial cells macrophages would be lost, so that subsequent cytotoxicity tests on the macrophage-depleted cells population would be negative. This in fact is what occurred in this study, but, since only 3 out of 25 cell strains were positive, it may not be of significance, while the negative results may indicate that there is no sensitising neoantigen present on rheumatoid synovial cells.

In the work of Griffiths et al. ${ }^{7}$ no cytotoxicity was observed in their experiments using autologous target and effector cells, and it might be relevant that their target cells had been in culture for long periods after several subcultures, so that no macrophages are likely to have been present in their target cell suspensions.

Only two of 21 chromium release cytotoxicity tests performed on target cells cultured in the presence of hydrocortisone were positive. The addition of hydrocortisone, therefore, failed to yield a population of target cells expressing neoantigens against which rheumatoid lymphocytes were sensitised.

Synovial cell cytotoxicity tests with the $\mathrm{MA}^{\circ}$ revealed a good correlation with the results obtained by the CRT technique. Out of 14 tests that were negative by MA, 13 were also negative by CRT. The total number of positive tests by MA was 4 out of 22 compared with 3 out of 25 with the CRT. It would nevertheless appear that cytotoxicity techniques involving autologous effector and target cells have not demonstrated the presence of neoantigens on rheumatoid synovial cells in culture.

Staff and patients at both the Northern General Hospital and the Princess Margaret Rose Orthopaedic Hospital, Edinburgh, are thanked for their help and co-operation in the course of this study. Thanks are especially due to Professor J. R. R. Duthie for his continued interest and support and to Dr Mary Norval for her helpful criticism. The work was financed by a grant provided by the Arthritis and Rheumatism Council.

\section{References}

1 Hedberg H, Kallen B. Studies on monoarticular cells derived from synovial fluid of patients with different types of arthritis. Cytotoxic effect on tissue cultured human fibroblasts. Acta Pathol Microbiol Scand 1964; 62: $117-88$.

2 Hedberg $\mathbf{H}$. Studies on synovial fluid in arthritis. The recurrence of monoarticular cells with in vitro cytotoxic effect. Acta Med Scand 1967; Supplement 479: 79-137.

3 Sukernik R, Hanin A, Mosolov A. The reaction of blood lymphocytes from patients with rheumatoid arthritis against human connective tissue cells in vitro. Clin Exp Immunol 1968; 3: 171-7.

4 MacLennan I C M, Loewi G. The effect of peripheral lymphocytes from patients with inflammatory joint diseases on human target cells in vitro. Clin Exp Immunol 1968; 3: 385-98. 
${ }^{5}$ Ghose T, Woodbury I F, Hansell M M. Interaction in vitro between synovial cells and autologous lymphocytes and sera from arthritis patients. J Clin Pathol 1975; 28 : 550-8.

6 Person D A, Sharp J T, Lidsky M D. The cytotoxicity of leukocytes and lymphocytes from patients with rheumatoid arthritis for synovial cells. J Clin Invest 1976; 58: 690-8.

7 Griffiths M M, Smith C B, Ward K R, Klauber M R. Cytotoxic activity of rheumatoid and normal lymphocytes against allogeneic and autologous synovial cells in vitro. $J$ Clin Invest 1976; 58: 613-22.

${ }^{8}$ Hart H, Marmion B P. Rubella virus and rheumatoid arthritis. Ann Rheum Dis 1977; 36: 3-12.

9 Bubenik J, Perlmann P, Helmstein K, Moberger G. Cellular and humoral immune responses to human urinary bladder carcinomas. Int J Cancer 1970; 5: 310-9.

10 Doherty P C, Blanden R V, Zinkernagel R M. Specificity of virus-immune effector $T$ cells for $H-2 K$ or $H-2 D$ compatible interactions. Transplant Rev 1976; 29: 89-124.

11 Schmitt-Verhulst A M, Sach D, Shearer G. Cell-mediated lympholysis of trinitrophenyl-modified autologous lymphocytes. J Exp Med 1976; 143: 211-7.

12 McMichael A J, Ting A, Zweeriak H J, Askonas B A. HLA restriction of cell-mediated lysis of influenza virus-infected human cells. Nature 1977; 270: 524-6.

13 Dickmeiss E, Soeberg B, Svejgaard A. Human cellmediated cytotoxicity against modified target cells is restricted by HLA. Nature 1977; 270; 526-8.

14 Hepburn B, McDuffie F C, Ritts R E. The macrophagelymphocyte rosette: its increased incidence among cells from rheumatoid synovial fluid. Arthritis Rheum 1974; 17: 1026-32.

15 Webb F W S, Baker M, Weisbart R, Bluestone R, Goldberg L S. Macrophage-lymphocyte clustering in rheumatoid arthritis. Ann Rheum Dis 1975; 34: 38-42.

16 Webb F W S, Goldberg L S, Bluestone R, Pearson C M. Retention of antigen by rabbit synovial macrophages. Br J Exp Pathol 1972; 53: 608-11.

17 Mackay J M K, Marmion B P, McCormick J M. Cocultivation of human cell lines with synovial fluids of patients with rheumatoid arthritis. Rheumatology $1975 ; 6$ : 346-52. 